This item was submitted to Loughborough's Research Repository by the author.

Items in Figshare are protected by copyright, with all rights reserved, unless otherwise indicated.

\title{
Improving retention strategies for IT professionals working in the public
} sector

PLEASE CITE THE PUBLISHED VERSION

PUBLISHER

(C) Elsevier B.V

VERSION

AM (Accepted Manuscript)

LICENCE

CC BY-NC-ND 4.0

\section{REPOSITORY RECORD}

Coombs, Crispin. 2019. "Improving Retention Strategies for IT Professionals Working in the Public Sector". figshare. https://hdl.handle.net/2134/4605. 
This item was submitted to Loughborough's Institutional Repository (https://dspace.lboro.ac.uk/) by the author and is made available under the following Creative Commons Licence conditions.

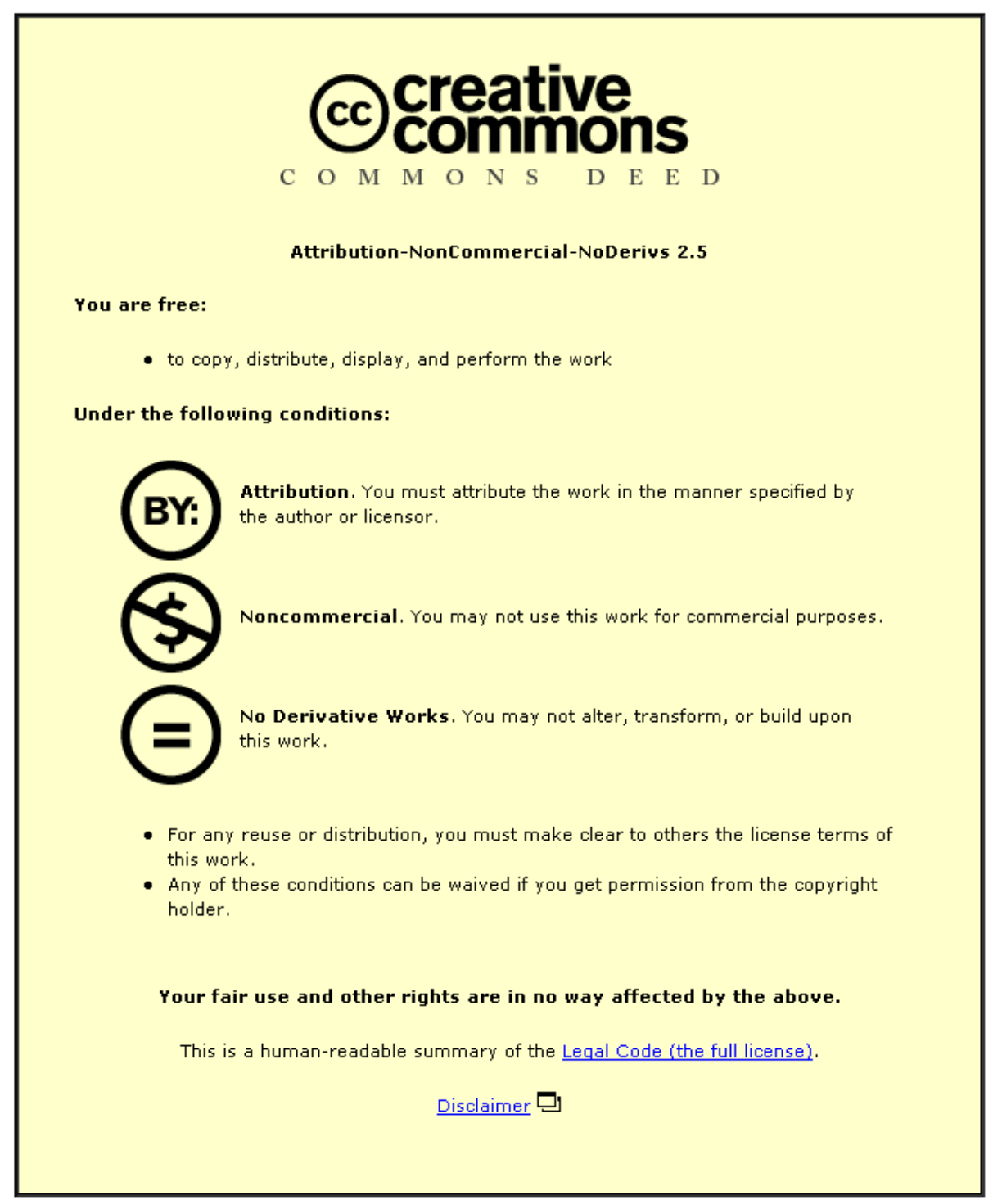

For the full text of this licence, please go to: http://creativecommons.org/licenses/by-nc-nd/2.5/ 


\title{
Improving Retention Strategies for IT Professionals Working in the Public Sector \\ Crispin R. Coombs ${ }^{1}$ \\ Business School, Loughborough University, UK
}

\begin{abstract}
Despite much research interest, effective retention of IT professionals has proved difficult for many public sector organizations. By concentrating on intention to leave, researchers may not have provided a clear way to formulate effective retention strategies. Consequently, we used intention to stay as an alternative lens to identify factors that can reduce turnover of IT professionals. Our findings indicated that attitudes, perceived behavioral control, and identification with the organization all had a statistically significant relationship with intention to stay; attitude was the strongest. It was concluded that existing retention strategies needed to be refocused on the issues that make IT staff stay; a number of practical recommendations for IT managers are presented.
\end{abstract}

\footnotetext{
${ }^{1}$ Dr Crispin Coombs, Business School, Loughborough University, Loughborough, Leics, UK, LE11 3TU, tel. 01509 228835, fax. 01509 223960, email. c.r.coombs@lboro.ac.uk
} 


\section{Introduction}

The IT profession in many countries has had high turnover rates in past years. These rates have ranged from $20 \%$ in the 1980 s, to $30 \%$ in the late 1990 s and between 5 to $14 \%$ in the 2000s [24]. More recent surveys suggested that while demand for IT professionals fell after the dot com bust, this trend was reversing, with the number of organizations adding exceeding those decreasing staff [26]. Indeed, it has been reported that attracting, developing, and retaining qualified IT staff was first in the top five IT executive management concerns for 2007/2008 [17].

High turnover of IS staff can result in failure of IT projects and persistent high turnover can result in projects being delayed, late, over budget or never completed. The effect of low morale due to burnout or low commitment may mirror the impact of employee turnover. Consequently, retaining a team of healthy, committed, and productive IT employees is vital for maintaining corporate advantage.

In the public sector, creating effective workforce management strategies to retain IT professionals is particularly difficult; there is competition between the public and private sector for well-trained, experienced IT employees. For example, some US state governments have reported IT employee turnover rates of over $11 \%$ despite increasing salaries and the introduction of flexi-time. The constraints of civil service systems that emphasize rules and regulations, control systems, political context, and limited autonomy and flexibility hinder the effective recruitment and retention of new staff [12]. These factors are further compounded with the tendency to purchase package solutions that reduce in-house work to system maintenance and relatively simple high 
level programming. As a result, IT professionals with portable skills across industries are able to find work with greater challenges and higher salaries elsewhere.

The public sector in the UK is also experiencing difficulties in the retention of IT professionals; problems in filling public sector vacancies are reported across all sectors and skill groups. The National Health Service (NHS) is particularly concerned; it currently requires a major overhaul of all core IS. This requires large numbers of skilled IT professionals to implement the national programme. The NHS requires detailed knowledge of the healthcare process and technologies that support it. Departing employees take with them valuable knowledge and expertise, so it is of paramount importance to retain current IT staff. However, despite the new challenges, the NHS has been having problems in retaining skilled professionals.

Therefore we decided to examine the factors that influenced the intention of IS professionals in the public sector to stay with their current employer. The specific objective was to investigate factors and consider the views of current IS professionals working in the NHS. The theory of planned behavior (TPB) was utilized as the underlying theoretical framework; it has been used to investigate an individual's intention to perform a given behavior [4].

\section{Turnover Research}

The serious negative impact that turnover can have on an organization has led to much interest in identifying the factors that predict IT professionals' intention to leave an organization. Several studies have been conducted and found that the major factors 
were job satisfaction with its antecedents, role conflict and ambiguity, and perceived organizational commitment.

However, developing appropriate retention strategies for IT professionals has proved difficult for many organizations. For example, in the US, managers expect IT professionals to remain in a job for only 30 months and for some roles the average tenure is only 19 months [11]. Furthermore, there are some IT professionals that appear to be quite content with their current job and yet continue to look for alternative employment [18]. These suggest that current turnover research fails to capture important aspects of the process or that staff turnover is not explained by work related factors alone.

One area that may help explain this paradox is that prior studies mainly considered the behavioral target of leaving rather than of staying. Maybe by concentrating on leaving, studies did not provide a clear way of formulating an effective retention strategy for IT staff.

It is common to assume that staying is the direct converse of leaving but Fuller et al. [9] observed that this assumes that the cognitive processes for both intentions are effectively the same. They argued that this symmetry is unlikely to occur. Essentially, the development of an individual's intention to leave is different from the intention to stay. Similarly, Lee and Mitchell’s [16] model of turnover, suggested that trajectory and strategic images for leaving or staying were different and that they involved different psychological processes. Consider the activities of a software engineer who is tempted to take a job with another employer providing better benefits. She chooses to 
stay with her employer because she likes the people with whom she works. Thus her motive for staying was different that for leaving [22]. Surveys of retained employees may therefore help to identify the strengths of an organization and help promote employee loyalty.

A further dimension that needs to be considered in attempting to refine existing retention strategies is the fact that IT professionals possess a number of distinct characteristics that differentiate them from other professions. Couger and Zawacki, [5] found that they had a strong need for accomplishment through learning and developing current skills and being challenged and stimulated in their work. They reported that programmers tended to have a low social need strength with less skill in verbal communication or need for interaction. They also found that IT managers were unique because of their high growth and low social needs. Consequently, our study investigated the issues that affected public sector IT staff in deciding to stay with their employer.

\section{Theoretical Framework}

The TPB [2] is shown in Figure 1. It has been successfully applied in a range of settings associated with recruitment and retention [13, 14, 25].

\section{Figure 1: Theory of Planned Behavior}

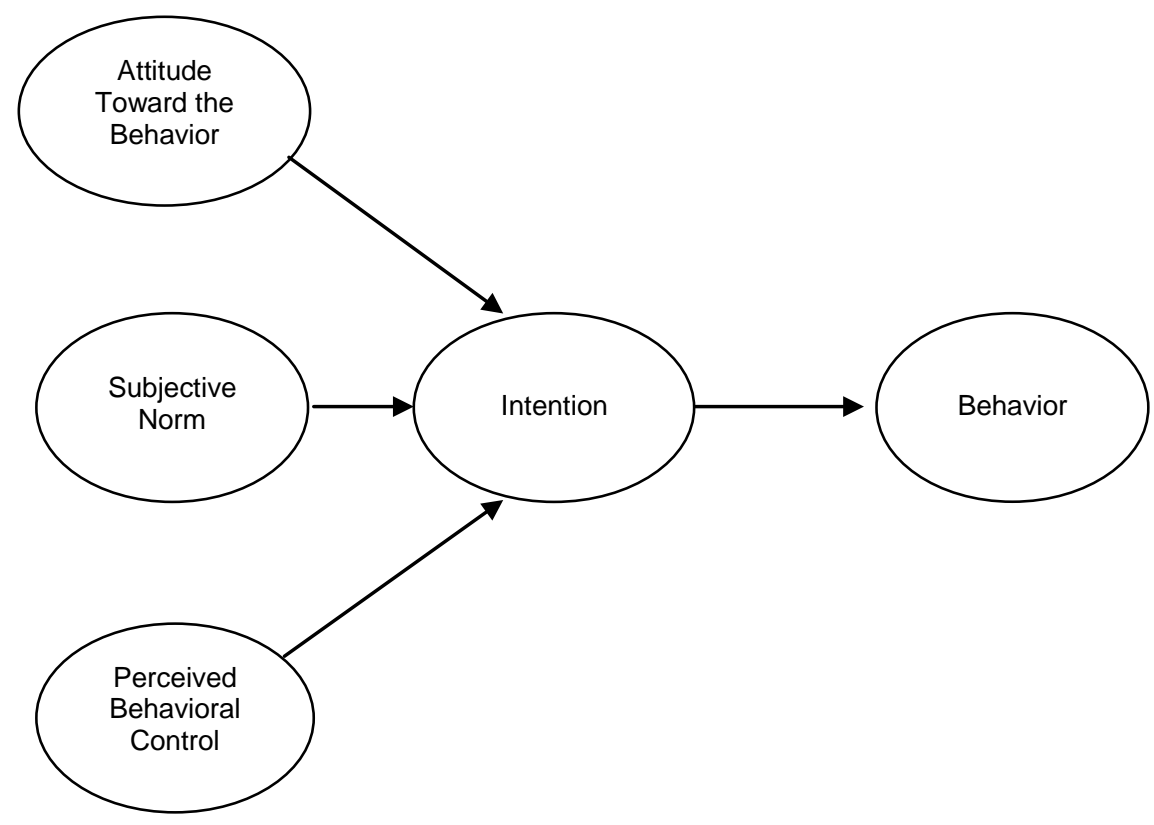


Ajzen argued that intention is the direct antecedent to performing a behavior, so the stronger the intention to engage in behavior, the more likely its performance. TPB proposed that there are three principal determinants of intention: attitude towards the behavior, the degree to which a person has a favorable or unfavorable evaluation of it; subjective norm (SN), the perceived social pressure to perform or not to perform it; and perceived behavioral control (PBC), the perceived ease or difficulty of performing it. In our study the focus was on intention to stay, since staying could not be investigated in the timescale of our experiment. Although, measuring actual behavior would have been desirable using a longitudinal study, such an approach may be undermined because actual departure depends upon current economic conditions. Hence four of the constructs were considered; actual behavior was omitted.

In addition, meta analyses of applications of TPB have reported that attitudes have frequently been found to contribute significantly to predictions of intention, whereas the results for SN and PBC have been more mixed. Given the importance of attitudes, we considered behavioral beliefs that may influence the attitudes of IT professionals toward continuing to work for the NHS. However, because the precise influence of SN and PBC is less clear we focused only on these constructs and did not consider their antecedents [normative beliefs (for SN) and control beliefs (for PBC)].

\subsection{Extending TPB}

It has been argued that sense of identity is likely to drive a person's behavior [23]. Some researchers viewed identity as being separate from other elements of the TPB and emphasized the social aspects of identity, including identity with a social construct or group. Identification with an organization has been found to be strongly negatively 
correlated with intention to leave an organization [20]. Some individual's working within the public sector have a sense of identification with their employer because they are contributing to the public good rather than purely profit focused [3]. We investigated whether working in a public sector health organization had any bearing on IT professionals' intention to continue working in the organization.

\section{Contextual Background}

The UK NHS was created in 1948. It brought together hospitals, general practitioners, opticians, dentists, and many other services into an integrated and organized service that provided healthcare for the population. Pay and Workforce Research [19] offered the most comprehensive, recent view of recruitment and retention issues of IT professionals in the NHS. Three core reasons were identified as reasons for not being able to fill vacancies. The first was that NHS salaries did not match those of competitors. Secondly, the poor image of the NHS due to mergers, insecurity, stress, high workload, insufficient resources, and few career or training pathways was seen as hindering its ability to recruit staff. Thirdly, the poor working environment and accommodation for IT functions reinforced the low profile and poor image of IT in the NHS. Overall, retaining staff was considered to be more important than recruiting new staff. Many managers cited the high levels of time and money needed to train and develop staff in the specialist skills needed to work in the NHS and that their loss had a major impact on their ability to deliver services. There was a feeling that many IT professionals used the NHS as a training ground to gather specialist skills and experience that enabled them to find better career and remuneration opportunities outside the NHS. A number of specific factors were identified as contributing to poor retention levels; these included excessive workload, high user expectations, and unrealistic demands causing stress and 
demotivation. A lack of job security due to merging organizations was thought to limit NHS in retaining senior staff.

The publication of Making Information Count [6] signified a greater focus on NHS issues. However, it did not indicate the extent to which these issues were being addressed. In addition, while the survey work was useful, it was largely descriptive, not driven by social science theory and not subjected to academic rigor.

\section{$5 \quad$ Research Objectives}

Using the TPB to guide the investigation. our study was intended to explore the factors that influenced the intention of IT professionals to continue working for the NHS. The framework for the study is shown in Figure 2.

Figure 2: Research Framework

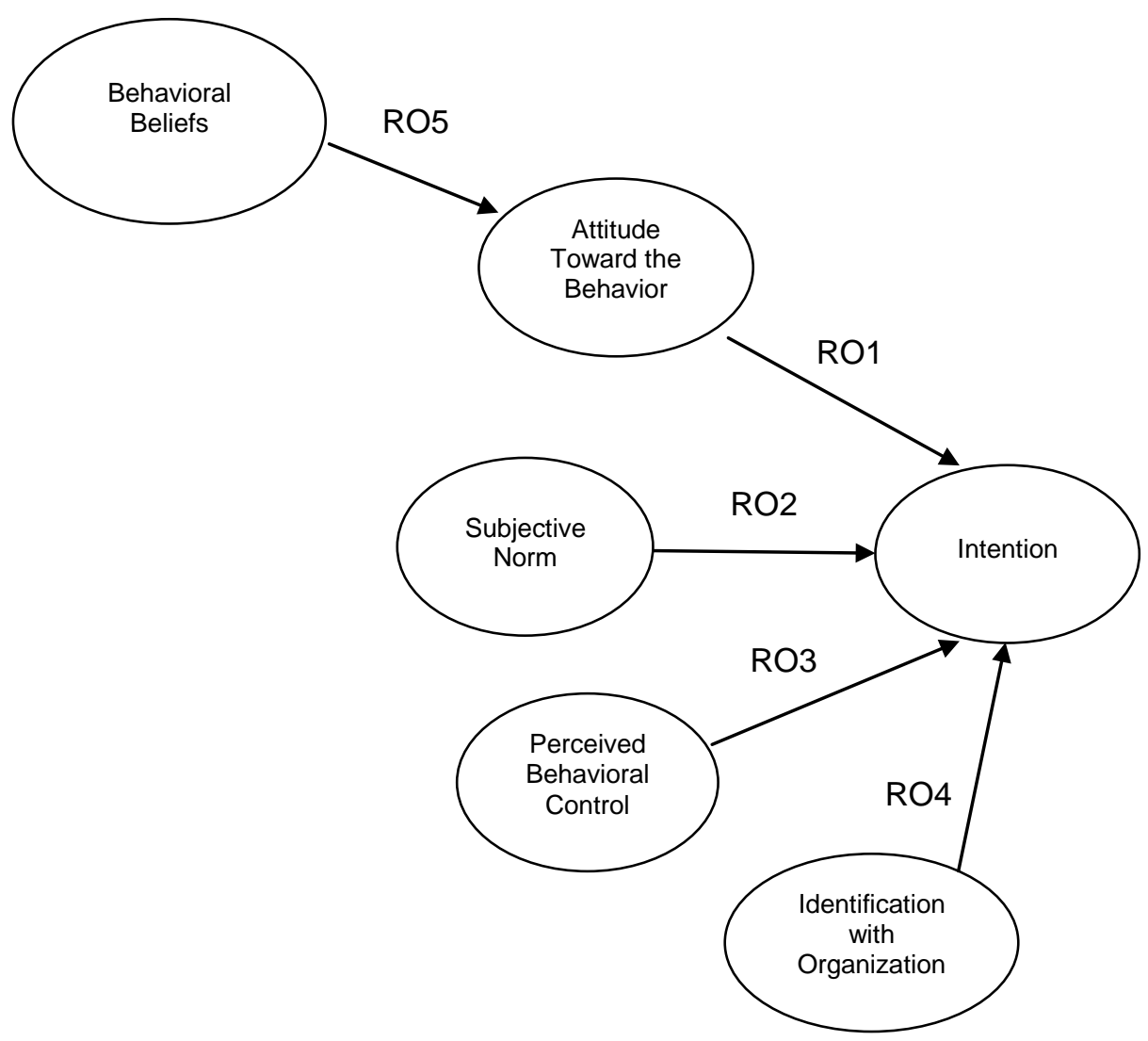


The study had five specific research objectives:

RO1 To explore the extent to which IT professionals' attitudes were associated with their intention to continue working for the NHS;

RO2 To explore the extent to which subjective norm was associated with IT professionals' intention to continue working for the NHS;

RO3 To explore the extent to which IT professionals’ beliefs regarding perceived behavioral control to stay in the NHS were associated with their intention to continue working for the NHS in health informatics;

RO4 To explore the extent to which IT professionals' identification with the NHS was associated with their intention to continue working for the NHS in health informatics;

RO5 To identify the behavioral beliefs that were associated with IT professionals' attitudes toward continuing to work for the NHS.

\section{Method}

The NHS tends to group information management and IT professionals into a single function and to use terms such as IM\&T (Information Management and Technology), ICT (Information and Communications Technology) and IT almost synonymously. This is further confused by the increasing use of Health Informatics. Making Information Count provided a definition of this discipline:

'The knowledge, skills and tools which enable information to be collected, managed, used and shared to support the delivery of healthcare and to promote health'. 
We also identified six core staff groups that were included in the discipline: ICT, including roles such as network management, help desk support, system support, and project management; IM staff, including roles such as business and data analysis, data protection, and planning and performance management; Health Informatics Senior Managers or Directors; Health Records staff, whose main role is to collate, organize, retrieve, and archive patient records; Knowledge Management staff, including librarians supporting health professionals in their education and training; and Clinical Informatics staff, including roles such as doctors and other clinical professionals helping develop and use electronic tools to support the use of the information in healthcare delivery. For our study the first three occupational groups were studied as they are the most closely aligned to the IT roles of other studies.

If behavioral beliefs are to be assessed, they must be identified as needed by IT staff working for the NHS. To address this, prior research on turnover of IT professionals in general was used to identify the beliefs most likely to be relevant for this study. Previous applications of TPB were reviewed to help develop appropriate questions and statements to measure each of the constructs and experience in developing a similar research instrument for earlier research of the author and colleagues was incorported. This experience helped improve the research instrument to ensure that it was appropriate for the NHS context (e.g., by adopting NHS terminology).

The research objectives were investigated using data collected by a survey using a questionnaire. Approval for data collection was received from the Northern and Yorkshire NHS Multi-Centre Research Ethics Committee. The questionnaire was extensively pretested by academics and IT professionals. On the whole the pre-testers 
were happy with the content of the questionnaire although a number of minor enhancements were suggested and some modifications were made.

\subsection{Research Instrument Design}

The questionnaire was divided into seven main sections. All items in it used a seven point Likert scale which ranged from strongly disagree, not at all important, or very unlikely to strongly agree, very important, or very likely, depending on the question. A summary of the items used is shown in Table 1. 
Table 1: Variables Used in Research Instrument and Results of Factor Analysis

\begin{tabular}{|c|c|c|c|c|c|}
\hline Construct & $\begin{array}{l}\text { No. } \\
\text { Items }\end{array}$ & $\begin{array}{l}\text { Factor } \\
\text { (Items) }\end{array}$ & Items in Factor & Source & $\begin{array}{l}\text { Item } \\
\text { Code }\end{array}$ \\
\hline \multirow[t]{3}{*}{ Intention } & 3 & $1(3)$ & $\begin{array}{l}\text { For me, continuing to work for the NHS as a health informatics } \\
\text { professional is very likely }\end{array}$ & {$[2]$} & I1 \\
\hline & & & $\begin{array}{l}\text { I intend to continue working for the NHS as a health informatics } \\
\text { professional }\end{array}$ & {$[2]$} & I1 \\
\hline & & & $\begin{array}{l}\text { I plan to continue working for the NHS as a health informatics } \\
\text { professional }\end{array}$ & {$[2]$} & I1 \\
\hline \multirow[t]{3}{*}{ Attitude } & 3 & $1(3)$ & $\begin{array}{l}\text { For me, continuing to work for the NHS as a health informatics } \\
\text { professional would be enjoyable }\end{array}$ & {$[2]$} & A1 \\
\hline & & & $\begin{array}{l}\text { My attitude towards working for the NHS as a health informatics } \\
\text { professional is positive }\end{array}$ & {$[2]$} & A1 \\
\hline & & & $\begin{array}{l}\text { For me, continuing to work for the NHS as a health informatics } \\
\text { professional would be pleasant }\end{array}$ & {$[2]$} & A1 \\
\hline \multirow[t]{3}{*}{$\begin{array}{l}\text { Subjective } \\
\text { Norm }\end{array}$} & 3 & $1(3)$ & $\begin{array}{l}\text { Most people who are important to me think that I should } \\
\text { continue to work for the NHS as a health informatics } \\
\text { professional }\end{array}$ & {$[2]$} & SN1 \\
\hline & & & $\begin{array}{l}\text { Most people, whose opinions I value would approve of me } \\
\text { continuing to work for the NHS as a health informatics } \\
\text { professional }\end{array}$ & {$[2]$} & SN1 \\
\hline & & & $\begin{array}{l}\text { If I continued to work for the NHS as a health informatics } \\
\text { professional, most of my family and/or friends would be proud }\end{array}$ & {$[2]$} & SN1 \\
\hline \multirow{3}{*}{$\begin{array}{l}\text { Perceived } \\
\text { Behavioral } \\
\text { Control }\end{array}$} & 3 & $0(3)$ & $\begin{array}{l}\text { Whether or not I continue to work for the NHS as a health } \\
\text { informatics professional is completely up to me }\end{array}$ & {$[2]$} & PBC1 \\
\hline & & & $\begin{array}{l}\text { I am confident that if I wanted to I could continue working for } \\
\text { the NHS as a health informatics professional }\end{array}$ & {$[2]$} & PBC2 \\
\hline & & & $\begin{array}{l}\text { It would be difficult for me to continue working in the NHS as a } \\
\text { health informatics professional }\end{array}$ & {$[2]$} & PBC3 \\
\hline \multirow{2}{*}{$\begin{array}{l}\text { Identificati } \\
\text { on with the } \\
\text { NHS }\end{array}$} & 2 & $1(2)$ & I am a strong believer in the principles of the NHS & {$[23]$} & ID1 \\
\hline & & & I am the type of person that feels at home working for the NHS & [23] & ID1 \\
\hline \multirow[t]{16}{*}{$\begin{array}{l}\text { Behavioral } \\
\text { Beliefs }\end{array}$} & 16 & $\begin{array}{l}4(5,3 \\
2,2)\end{array}$ & $\begin{array}{l}\text { I will be helping patient care processes through health } \\
\text { informatics }\end{array}$ & {$[19]$} & $\mathrm{BB} 1$ \\
\hline & & & I will have challenging tasks at work & [1] & BB1 \\
\hline & & & I will be working as part of a team & [8] & BB1 \\
\hline & & & I will have interesting tasks at work & [1] & BB1 \\
\hline & & & I will be empowered to make decisions regarding my work & [19] & BB1 \\
\hline & & & I will be working under a lot of pressure & [19] & BB2 \\
\hline & & & $\begin{array}{l}\text { I will have to work long hours (e.g. well over my contracted } \\
\text { hours) }\end{array}$ & {$[19]$} & BB2 \\
\hline & & & I will be overworked & [19] & BB2 \\
\hline & & & $\begin{array}{l}\text { I will be working where there are clear policies on gender } \\
\text { equality }\end{array}$ & [3] & BB3 \\
\hline & & & I will be working where there are clear policies on race equality & [3] & BB3 \\
\hline & & & I will have the opportunity to use new technology & [19] & BB4 \\
\hline & & & I will have the opportunity to be trained to use new technology & [19] & BB4 \\
\hline & & & I will be working for low pay & [19] & $\begin{array}{l}\text { Dropp } \\
\text { ed }\end{array}$ \\
\hline & & & I will have a secure job & {$[19]$} & $\begin{array}{l}\text { Dropp } \\
\text { ed }\end{array}$ \\
\hline & & & I will have the freedom to choose the hours I work & [8] & $\begin{array}{l}\text { Dropp } \\
\text { ed }\end{array}$ \\
\hline & & & I will have a lack of promotion opportunities & [8] & $\begin{array}{l}\text { Dropp } \\
\text { ed }\end{array}$ \\
\hline
\end{tabular}




\subsubsection{Intention}

Respondents were asked to complete three questions to measure their level of intention to continue working for the NHS in health informatics. These questions asked about the likelihood, plans to, and intention to continue working for the NHS. Three items were used to assess overall intention, so that this key variable was not assessed by only one question. Factor analysis of the responses to these three items indicated that they depended on a single factor, and reliability analysis, using the alpha coefficient, showed very strong reliability at 0.93 . Therefore these three items were combined to form a single intention measure (I1).

\subsubsection{Attitude towards the behavior}

Respondents' attitudes to the NHS were measured by asking them to indicate to what extent they thought continuing to work for the NHS would be enjoyable, pleasant, or positive. Factor analysis of these three items indicated they formed a single factor and reliability analysis produced a good alpha of 0.86 . Therefore the items were combined to form a single attitude measure (A1).

\subsubsection{Subjective norm}

SN was measured by three items each asking respondents to indicate the extent to which they felt social pressure to stay with the NHS from others who were important to them. For example, whether the people would be proud, approve of their decision to stay, etc. Factor analysis of the three items indicated a single factor (SN1) and the combined three-item scale had an alpha reliability coefficient of 0.69 . 


\subsubsection{Perceived behavioral control}

Three questions measured the perceived behavioral control that respondents felt over their ability to decide whether to continue working for the NHS as a health informatics professional: whether the decision was 'up to them' or they felt confident that they could continue working for the NHS if they wished. Although factor analysis of these three items indicated a single factor, the alpha reliability coefficient was only 0.56 . Hair et al. [10] stated that only alpha values greater than 0.60 should be accepted in combining multiple items into a single scale. Consequently, the three items were not combined and were left as individual elements (PBC1, PBC2 and PBC3).

\subsubsection{Behavioral beliefs}

Behavioral beliefs were investigated using 16 different statements about the NHS that allowed respondents to show whether or how they expected to continue working for the NHS. For example, respondents were asked to indicate whether they thought they would work as part of a team, under pressure, and have a variety of work. The statements were drawn from a review of the issues most frequently identified as important in IT staff turnover. Inevitably, not all issues could be included in our research instrument as it would have made the questionnaire excessively long. Therefore, only those issues that had been identified as most important were included. These items were analyzed in terms of their individual associations with attitude. The item scores were subjected to exploratory factor analysis using principal components analysis with varimax rotation to identify any broader themes. One item, freedom to choose the hours I work had a factor loading of less than .4 and was subsequently ignored. Although five factors were identified, the fifth, with three items, failed to 
achieve an acceptable alpha reliability coefficient (0.50); these three items were therefore dropped from the regression analysis. The four remaining factors were:

1. Positive Work Features (BB1) which included five items: Empowered to make decisions regarding my work, Challenging tasks at work, Interesting tasks at work, Helping patient care processes through heath informatics, and Working as part of a team. The alpha internal reliability of this scale was 0.79 .

2. Pressure/Hours (BB2) which included three items: Working under a lot of pressure, Overworked and Having to work long hours. The alpha coefficient for this group was 0.83 . All items were negatively worded, so that a high score indicated negative perception.

3. Equality (BB3) included two items: Working where there are clear policies on gender equality, and Working where there are clear policies on race equality. The alpha coefficient was 0.91 .

4. Technical Development (BB4) included two items: The opportunity to be trained on new technology, and The opportunity to use new technology. Its alpha coefficient was 0.76 .

\subsubsection{Identification with the NHS}

Two questions were used to assess the extent to which respondents personally identified with the NHS. These were, I am a strong believer in the principles of the NHS and I am the type of person who feels at home working for the NHS. Factor analysis of these items indicated a single factor and they were combined into a two-item scale with an alpha reliability coefficient of 0.62 . 


\subsubsection{Demographics}

Respondents' backgrounds: in which area of health informatics they were working and for which type of healthcare organization they were working were also collected. Respondents were also asked to provide information about their background (gender, marital status, age and ethnic background). Respondents were also provided the opportunity to make additional comments about the research.

\section{Results}

The questionnaire was targeted at named IM\&T Managers and Computer Network Managers in each Trust, Primary Care Trust, Care Trust and Strategic Health Authority in England and Wales. As there is no central register of NHS informatics staff the contact details were purchased from Binley’s, a Health Information Company and were drawn from their database of all NHS management staff containing 33,748 contacts. The extraction from the management database provided 1,144 contacts. A pilot survey of 119 questionnaires (10\% of the total sample) was sent to a stratified random sample of contacts from the database in January 2005. Twenty two responses were received giving an initial response rate of $18 \%$. Analysis of these indicated no problems with the content or structure of the questionnaire and therefore no alterations were made. Including the pilot, a total of 207 responses were received, giving a response rate of $18 \%$ which is similar to other research studies in this area [15] and provided a useable sample size.

The sample was tested for non-response bias. As the survey was anonymous it was not possible to identify who had not responded. We used an alternative test: assuming that those who responded late were proxies for those that did not respond; data from the first 
$10 \%$ of respondents (based on the postmark of returned envelopes) was compared with data for the last $10 \%$. There were no significant differences between the respondents in these two sets.

\subsection{Demographics}

Table 2 shows the demographics of the respondents. Of the three most common job roles, males accounted for $84 \%$ of the ICT staff and $68 \%$ of Senior Health Informatics Managers. The age of respondents ranged from 24 to 62 with an average age of 44 . These figures are in line with the wider gender and age profile of IT and Telecoms occupations in the UK [7]. It was difficult to assess how representative the sample was; there has been little workforce planning undertaken by the NHS. Estimates suggest that there are between 21,000 and 25,000 NHS informatics staff in in England (no figures are available for Wales), but there is no information about their age or gender. In terms of job roles, senior managers and IM staff appear to be over-represented and ICT staff under-represented in the respondent sample compared to the population. In percentage terms the difference is greatest for senior managers, but the target group was restricted to IM\&T and Computer Network Managers. However, the respondent sample and therefore our findings, may be aligned with the views of IT managers rather than other IT staff groups.

Table 2 Demographics of Respondents

\begin{tabular}{llrll}
\hline Sex & & $\begin{array}{r}\text { No. of } \\
\text { Respondents }\end{array}$ & Respondent sample \% & $\begin{array}{l}\text { NHS informatics staff } \\
\text { population in England } \\
\end{array}$ \\
& Males & 136 & $(66 \%)$ & $\begin{array}{l}\text { n/a } \\
\text { n/a }\end{array}$ \\
& Females & 70 & $(34 \%)$ & \\
\hline Age & & & & \\
& $20-29$ & 3 & $(2 \%)$ & n/a \\
& $30-39$ & 53 & $(29 \%)$ & n/a \\
& $40-49$ & 72 & $(40 \%)$ & n/a \\
& $50-59$ & 48 & $(27 \%)$ & \\
\hline
\end{tabular}


Facilities Officer

Public Health Intelligence

$\begin{array}{rll}120 & (59 \%) & 7 \% \\ 42 & (21 \%) & 18 \% \\ 37 & (18 \%) & 37 \% \\ 3 & (2 \%) & 9 \% \\ 1 & (1 \%) & 3 \% \\ 1 & (1 \%) & \text { n/a } \\ 1 & (1 \%) & \text { n/a }\end{array}$

\subsection{Intention to Stay}

The mean score of the three questions that made up the intention scale was 5.14 with a standard deviation of 1.39 . So, on average, respondents were reporting a moderately strong intention to continue working for the NHS as health informatics professionals. The spread of scores is quite large; thus some had a strong intention to continue working in the NHS while others were likely to consider other offers.

\subsection{Attitude}

The mean score of the three questions assessing attitude was 4.91 with a standard deviation of 1.21. Again, this suggests a moderately positive attitude on average. The spread was again quite large, but less than for intention, suggesting that a wider range of factors influenced intention than attitude.

In order to examine the associations between each individual construct and intention to stay, a correlation analysis was conducted. The relation between attitude and intention for the whole was 0.67 , with a p-value $<0.01$. This indicated that the more positive a person's attitude, the more likely they would stay working in the NHS. 


\subsection{Subjective Norm}

The mean score for subjective norm was 4.84 with a standard deviation of 0.99 . This indicated that there was moderate social approval for the idea of continuing to work for the NHS. This was highly correlated (0.51) with intention towards doing so. This suggested that the opinions of people who are important to the respondents had considerable impact on the probability that a person would continue to work for the NHS.

\subsection{Perceived Behavioral Control}

On average the respondents felt a high sense of personal control over continuing to work for the NHS (5.63) - they were confident they could do so (5.80), and anticipated few difficulties (2.20). Both PBC1 and PBC2 had positive correlations with intention (0.20 and 0.24). PBC3 (which was negatively worded) had a strong negative correlation with intention (-0.52) indicating that those respondents who did not anticipate any difficulties in continuing to work for the NHS strongly intended to do so.

\subsection{Behavioral Beliefs}

The means and standard deviations for respondents' behavioral beliefs are shown in Table 3, with the items in descending order of endorsement. It is evident that some perceptions of working for the NHS were strongly and almost universally held. The highest was challenging tasks at work, closely followed by working under a lot of pressure and as part of a team.

It can be seen that a range of beliefs of working for the NHS are associated with continuing to work for it. The highest correlations were with having interesting tasks at 
work and empowered to make decisions regarding my work. This indicated that people are first and foremost looking at the actual work activities they undertake rather than pay levels or the way they work with colleagues

Table 3:Behavioral Beliefs

\begin{tabular}{lccc}
\hline Items & Perceptions of Continuing to Work for the NHS \\
\hline & $\begin{array}{c}\text { Mean } \\
\text { (Min }=1 \text { : Max }=7)\end{array}$ & SD & $\begin{array}{c}\text { Correlation with } \\
\text { Attitude }\end{array}$ \\
Challenging tasks at work & 6.09 & 0.93 & $0.36^{* *}$ \\
Working under a lot of pressure & 5.99 & 1.04 & $-0.14^{*}$ \\
Working as part of a team & 5.87 & 0.99 & $0.30^{* *}$ \\
Working where there are clear policies on race & 5.72 & 1.22 & $0.21^{* *}$ \\
equality & & & $0.39^{* *}$ \\
Helping patient care processes through health & 5.67 & 1.30 & $0.19^{* *}$ \\
informatics & & & \\
Working where there are clear policies on gender & 5.60 & 1.35 & $-0.20^{* *}$ \\
equality & & & $0.55^{* *}$ \\
Overworked & 5.57 & 1.33 & $0.53^{* *}$ \\
Interesting tasks at work & 5.57 & 1.10 & 0.05 \\
Empowered to make decisions regarding my work & 5.45 & 1.27 & $0.34^{* *}$ \\
Work long hours (e.g. well over my contracted & 5.31 & 1.43 & $0.35^{* *}$ \\
hours) & & 1.21 & $-0.34^{* *}$ \\
Opportunity to use new technology & 5.27 & 1.51 & $0.29^{* *}$ \\
Opportunity to be trained to use new technology & 4.83 & 1.67 & $0.20^{* *}$ \\
Lack of promotion opportunities & 4.77 & 1.42 & $-0.18^{*}$ \\
Secure job & 4.66 & 1.63 & \\
Freedom to choose the hours I work & 4.55 & 3.73 & \\
Working for low pay & &
\end{tabular}

**. Correlation is significant at the 0.01 level (2-tailed)

*. Correlation is significant at the 0.05 level (2-tailed)

\subsection{Identification with the NHS}

The mean score for identification with the NHS was 5.73 with a standard deviation of

1.06. This indicated that the respondents felt a reasonably strong sense of identification with the NHS. Relatively few did not identify with the NHS. The extent to which a person did identify was correlated with his or her intention to continue working for it (0.40). Therefore, it appeared that the more people identified with the NHS, the more positive they felt about continuing to work for it. 


\subsection{Predictors of Intention}

In order to further explore the research objectives and examine the relative importance of the different perceptions and values held by respondents, two multiple regression analyses were conducted. Results of these are shown in Table 4.

Table 4: Results of Regression Analyses

\begin{tabular}{|c|c|c|c|c|}
\hline Analysis & Research Objectives & $\begin{array}{l}\text { Independent } \\
\text { Variables }\end{array}$ & $\begin{array}{l}\text { Dependent } \\
\text { Variable }\end{array}$ & Beta Weights \\
\hline \multirow{6}{*}{1} & \multirow{6}{*}{ RO1, RO2, RO3, RO4 } & A1 & \multirow{6}{*}{ 年 } & $0.46 * * *$ \\
\hline & & SN1 & & $0.14^{*}$ \\
\hline & & PBC1 & & -0.03 \\
\hline & & PBC2 & & 0.00 \\
\hline & & РBC3 & & $-0.21 * * *$ \\
\hline & & ID1 & & $0.11^{*}$ \\
\hline \multirow{4}{*}{2} & \multirow{4}{*}{ RO5 } & BB1 & \multirow{4}{*}{$\mathrm{A} 1$} & $0.62 * * *$ \\
\hline & & BB2 & & $-0.17 * *$ \\
\hline & & BB3 & & 0.00 \\
\hline & & BB4 & & $0.12^{*}$ \\
\hline
\end{tabular}

There was a strong positive association between respondents' attitudes and their intention to stay in the NHS (RO1) and this had the strongest direct influence on intention. SN also contributed to predicting intention, but not as much as attitude (RO2). This indicated that the more positive managers, colleagues, close friends and family opinions, the greater respondents' intention to continue to work for the NHS. The negatively worded perceived behavioral control item (PBC3) also had a negative association with intention; this was stronger than SN, but less than attitude (RO3). The results suggested that if respondents perceived that it would be difficult for them to continue working for the NHS, then their intention to do so diminished. Finally, identification with the NHS also had a positive association with intention (RO4). This 
indicated that the more a IT professional identified with the NHS, and felt that it was aligned with their principles, the more likely they were to continue working for it.

Three behavioral beliefs had a significant influence on the attitude of respondents: positive work features, pressure/hours, and technical development (RO5). Positive work features (empowerment, challenging and interesting tasks, helping patient care processes, and working as part of a team) had the strongest association with attitude while perceptions of pressure/hours had a relatively minor negative association with attitude. Technical development opportunities also had a positive association with intention indicating that having the opportunity to be trained on and use new technology was important to respondents' intention to stay working for the NHS. Thus positive aspects of NHS work were more powerful encouragers than negative aspects were discouragers.

\section{Discussion}

Our study focused on IT professionals' intention to stay with their current employer, rather than intention to leave. By adopting this perspective, we were able to provide fresh insight into the characteristics that influence decision to stay or leave an employer.

The NHS has a history of taking on very large, ambitious and complex IT projects, many of which have been late in their delivery. Consequently, IT projects within the NHS appear to be likely to change from being interesting and challenging tasks to stressful chores. 
The results indicated that the more that IT professionals identified with the NHS, the more likely they were to stay. However, IT managers need to be careful not to overload their staff and rely too heavily on loyalty as a reason that IT staff stay.

Three other observations can be made. Firstly, perceived value of the IT work in improving patient care may be viewed as a role with greater value and more worthwhile than performing a similar role in a profit making company. Other studies have found that 'feeling what I do matters' is important [21]; it is important that managers point out that their IT professionals are building and maintaining systems that help save lives.

Secondly, working as part of team is a positive factor for IT staff retention. IT staff normally are thought to have a low social need and prefer working on their own with almost no interaction outside their department. However, IT professionals appear to have a need for tasks that meet interpersonal needs through teamwork, contact with users, and an opportunity to develop professional friendships. Ferratt et al. [8] add that the modern role of IT professionals has extended with emphasis on interaction.

Thirdly, the study also provided evidence to show that IT professionals' intentions to continue working for an employer were influenced by subjective norm, which suggested that the factors influencing the opinions of people important to the IT professional may also have significant effect on decisions. Prior work showed that the media image of the NHS had a strong influence on people's opinions of working for the NHS. Consequently, the more "good press" that NHS generates, the more positive will be the feelings of the people important to the IT professional and hence of his or her continuing to work for the NHS. 
It appears that the lack of successful retention strategies may be due to insufficient attention to job characteristics that are likely to retain staff. Efforts have concentrated on increasing salaries and introducing flexi-time. However, our findings suggested that there were other job characteristics that were more important: IT staff should be offered more autonomy being allowed to make decisions about their work, which should be challenging and interesting with opportunities to apply new technology. IT staff need more than day-to-day maintenance of existing systems to keep their motivation high. Having greater contact with external stakeholders within the organization, may also help reinforce the important message that their work can help save patient lives.

\section{Concluding Remarks and Limitations}

Overall, the results of this study help to explain why current retention strategies for IT staff in public sector organizations are not providing the desired level of retention. Public sector IT managers should address some aspects to improve retention of precious IT staff; they need to consider both job design and issues such as the influence of people important to IT professionals and how their views can influence an IT professional's decision making about a career move.

Our findings are, however, subject to a number of limitations. The data was drawn from a single organizational sector and consequently, they have limited generalisibility. However, the NHS is the largest employer in Europe and is a vast and complex organization that will have many issues that apply to other sectors. The study only employed a single research strategy, namely a questionnaire survey, and while surveys have a number of strengths, they do not allow respondents an opportunity to explain their answers or add information. It should also be noted that a large percentage of the 
respondents to the survey consisted of senior IT staff. Consequently, the findings and associated recommendations may be more closely linked to the needs of senior IT staff than junior IT professionals. A final limitation is that it attempts to predict behavior through measuring intention. 


\section{References}

1 R. Agarwal, T.W. Ferratt, Enduring practices for managing IT professionals, Communications of the ACM 45 (9), 2002, pp. 73-79.

2 I. Ajzen, The theory of planned behavior, Organizational Behavior and Human Decision Processes 50, 1991, pp. 179-211.

3 J. Arnold, C.R. Coombs, A.J. Wilkinson, J. Loan Clarke, J. Park, D. Preston, Corporate images of the United Kingdom National Health Service: Implications for the recruitment and retention of nursing and allied profession staff, Corporate Reputation Review, 6 (3), 2003, pp. 223-238.

4 J. Arnold, C.R. Coombs, A.J. Wilkinson, J. Loan Clarke, J. Park, D. Preston, How well can the Theory of Planned Behavior account for occupational intentions?, Journal of Vocational Behavior, 69 (3), 2006, pp. 374-390.

5 J. D. Couger, R. A. Zawacki, Motivating and managing computer professionals, John Wiley \& Sons, Inc, New York, 1980.

6 Department of Health, Making Information Count: A Human Resources Strategy for Health Informatics Professionals, Department of Health, London, 2002.

$7 \quad$ E-Skills UK, IT \& Telecoms Insights 2008: Profiles of the Industry and Workforce, E-Skills UK, London, 2008.

8 T. W. Ferratt, R. Agarwal, J. Ellen Moore, C. V. Brown, Observations from 'The Front': IT executives on practices to recruit and retain information technology professionals, in: Proceedings of the ACM SIGCPR Conference, 1999.

9 J. B. Fuller, K. Hester, P. Dickson, B. J. Allison, M. Birdseye, a closer look at select cognitive precursors to organizational turnover: what has been missed and why, Psychological Reports 78 (3), 1996, pp. 1331-1352.

10 J. F. Hair, R.E. Anderson, R.L. Tatham, W.C. Black, Multivariate Data Analysis with Readings, Prentice Hall, Engelwood Cliffs, NJ, 1995.

11 ITAA, Adding Value...Growing Careers, Information Technology Association of America Annual Workforce Development Survey, ITAA: Arlington VA, 2004.

12 S. Kim, Factors affecting state government information technology employee turnover intentions, The American Review of Public Administration 35, 2005, pp. 137-156.

13 M. Krausz, M. Koslowsky, N. Shalom, N. Elyakim, Predictors of intentions to leave the ward, the hospital, and the nursing profession: a longitudinal study, Journal of Organizational Behavior 16, 1995, pp. 277-288.

14 I. M. Lane, R. C. Matthews, P. H. Presholdt, Determinants of nurses' intentions to leave their profession, Journal of Organizational Behavior 9, 1988, pp. 367372.

15 P.C.B. Lee, Social support and leaving intention among computer professionals, Information and Management 41, 2004, pp. 323-334.

16 T.W. Lee, T.R. Mitchell, An alternative approach: the unfolding model of voluntary employee turnover, Academy of Management Review 19, 1994, pp. 51-89.

17 J. Luftman, R. Kempaiah, Key issues for IT executives 2007, MIT Quarterly Executive 7 (2), 2008, pp.99-112.

18 F. Niederman, M. R. Sumner, Decision paths affecting turnover among information technology professionals, in Proceedings of the SIGMIS Conference, Philadelphia, Pennsylvania, USA, 2003. 
19 Pay and Workforce Research, IM\&T Recruitment and Retention Survey 2000, Pay and Workforce Research, Harrogate, 2001.

20 M. Riketta, R. Van Dick, Foci of attachment in organizations: a meta-analytic comparison of the strength and correlates of workgroup versus organizational identification and commitment, Journal of Vocational Behavior, 67, 2005, pp.490-510.

21 M. W. Schriner, More than money, Healthcare Informatics Online February, 1999, pp. 72-74.

22 R. P. Steel, R. W. Griffeth, P. W. Hom, Practical retention policy for the practical manager, Academy of Management Executive 16, 2002, pp. 149-164.

23 D. J. Terry, M. A. Hogg, K. M. White, The theory of planned behavior: selfidentity, social identity and group norms. British Journal of Social Psychology 38, 1999, pp. 225-244.

24 D. Tunick Morello, C. Claps, (2000). Building a compelling place to work: new heights in IT human resources management, No. R-10-5444, Gartner Group, Inc: Stamford, 2000.

25 E. A. J. Van Hooft, M. P. Born, T. W. Taris, H. van der Flier, Job search and the theory of planned behavior: minority-majority group differences in the Netherlands, Journal of Vocational Behavior 65, 2004, pp. 366-399.

26 P. Zwieg, K.M. Kaiser, C.M. Beath, C. Bullen, K.P. Gallagher, T. Goles, J. Howland, J.C. Simon, P. Abbott, P. Abraham, T. Abraham, E. Carmel, R. Evaristo, S. Hawk, M. Lacity, M.J. Gallivan, S. Kelly, J.G. Mooney, C. Ranganathan, J.W. Rottman, T. Ryan, R. Wion, The information technology workforce: trends and implications 2005-2008, MIT Quarterly Executive 5 (2), 2006, pp.47-54. 
Section: Research

Vita of Author: Dr. Crispin R. Coombs is a Lecturer in Information Systems and a member of the Management Science, Information Systems and Operational Research Group, Business School, Loughborough University, UK. Dr. Coombs earned his PhD in Information Systems from Loughborough University. Dr. Coombs focuses on human and organizational issues associated with systems development projects in both the public and private sectors. His work has been published at such journals as Journal of End User Computing, European Journal of Information Systems, and the Journal of Vocational Behavior.

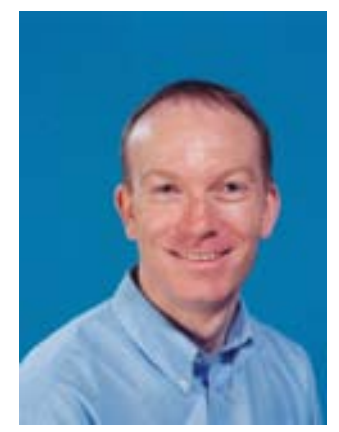

Original Submission Date: 10 November 2005

Revised Submission Date: 21 December 2007

Revised Submission Date $2^{\text {nd }}$ Pass: 22 December 2008

Final Acceptance Date: 14 February 2009

Fax Number: +44 (0)1509 223960

Keywords: Retention, IT Professionals, NHS, Healthcare, Theory of Planned Behavior 